\title{
A comparison of leak pressures between esophageal to esophageal anastomosis and esophageal to jejunal anastomosis
}

\author{
Devin P. Cunningham, John R. Middleton, F. A. Mann* \\ Department of Veterinary Medicine and Surgery, College of Veterinary Medicine, University of Missouri, \\ Columbia, MO 65211, USA
}

\begin{abstract}
The goal of this study was to determine if there was a difference in leak pressure between esophageal-esophageal anastomosis and esophageal-jejunal anastomosis when using cadaveric porcine tissue. Leak pressures were recorded for esophagealesophageal anastomosis (Group 1 [control group], $\mathrm{n}=7$ ), cranial esophageal-jejunal anastomosis (Group 2, $\mathrm{n}=7$ ), and jejunal-caudal esophageal anastomosis (Group 3, $\mathrm{n}=6$ ). Each anastomosis was performed using polydioxanone sutures in a simple interrupted pattern. Results were analyzed using one-way analysis of variance. Mean \pm SD of the leak pressures for groups 1, 2, and 3 were $46.1 \pm 15.9,36.5 \pm 13.6$, and $50.9 \pm 11.1 \mathrm{mmHg}$, respectively $(p=0.18)$. When the results from groups 2 and 3 were combined and compared to that for Group 1, the mean \pm SD leak pressures were $46.1 \pm 15.9$ and $43.1 \pm 14.2 \mathrm{mmHg}$, respectively $(p=0.67)$. These results provide preliminary evidence that the jejunum may be a suitable option for use in esophageal replacement surgery; however, future studies of in vivo factors influencing the integrity of esophageal-jejunal anastomoses, including histologic evaluation of esophageal-jejunal anastomosis healing, are needed.
\end{abstract}

Keywords: esophageal surgery, leak pressure, esophageal replacement, esophagojejunal anastomosis

*Corresponding author

F. A. Mann

Department of Veterinary Medicine and Surgery, College of Veterinary Medicine, University of Missouri, 900 East Campus Drive, Columbia, MO 65211, USA

Tel: +1-573-882-7821

Fax: $+1-573-884-5444$

E-mail: MannF@missouri.edu

ORCID:

Devin P. Cunningham

https://orcid.org/0000-0001-5676-7815

John R. Middleton

https://orcid.org/0000-0003-0791-6604

F. A. Mann

https://orcid.org/0000-0001-6181-0216

Conflict of Interest

The authors declare no conflicts of interest.

Received: October 18, 2018

Revised: February 5, 2019

Accepted: March 7, 2019

\section{Introduction}

Esophageal surgery, although rare in small animals, can be used to alleviate foreign body obstructions and correct perforations, strictures, neoplasia, esophageal diverticula, and esophageal fistula [1-4]. Major complications of esophageal surgery include dehiscence, leakage, and luminal stenosis. The esophagus is at higher risk for dehiscence than other parts of the digestive system [5-10]. Factors that may contribute to dehiscence are lack of a serosal layer, which is important for optimal healing, presence of saliva and food boluses, and constant motion of the esophagus as a result of head, neck, and respiratory movements $[5-7,9,11,12]$. The esophagus does not heal well under tension, and removal of as little as $2 \mathrm{~cm}$ of esophageal length causes tension and increases the risk of dehiscence [1,9]. Esophageal replacement is undertaken in human medicine in cases in which large defects of the esophagus need repair [5,13-18].

Esophageal replacement can be performed with muscle, stomach, colon, or small intestine tissue with or without vascular anastomoses [1,6-8,10]. However, clinical application in small animals is limited [7,19]. Although technically demanding, replacement with jejunum is becoming popular in human medicine due to good long-term outcomes [20-23]. In both dogs and humans, leakage from the anastomotic site is one of the most common complications of esophageal replacement surgery when using an intestinal segment $[5,18]$. To the authors' knowledge, there are no studies evaluating leak pressure at the anastomosis when using bowel segments for replacement of the esophagus.

Cadaveric tissue is a useful model for testing enterotomy closure and measuring leak pressure [3,24-26]. Due to anatomical differences between the jejunum and esophagus [27], knowledge of leakage pressure at an esophagealjejunal anastomosis site could provide preliminary data relevant to clinical application of esophageal replacement surgery. Leak pressure also serves as a proxy for luminal distension and tension at the incision site. The purpose of this study was to compare leak pressures of esophageal-esophageal (control) 
and esophageal-jejunal anastomoses to gain initial insight into whether jejunum may be a suitable tissue for repair of esophageal defects in animals.

\section{Materials and Methods}

\section{Study subjects and tissues}

This study was conducted at the College of Veterinary Medicine University of Missouri, USA. Study subjects consisted of 7 pigs that were euthanized for reasons unrelated to this study. Segments of jejunum and esophagus were harvested from each cadaver immediately after euthanasia. The thoracic esophagus was transected at the thoracic inlet and at the esophageal hiatus at the diaphragm. The length of the harvested esophagus was not recorded, but pigs were of uniform age and body weight, and the variability in the length of the excised tissue was minimal. A single 3-0 nylon simple interrupted suture was placed at the caudal aspect of the harvested esophageal segment to differentiate between its cranial and caudal ends. The jejunum was harvested by measuring $5 \mathrm{~cm}$ orally from the jejunal-ileal junction, and then $8 \mathrm{~cm}$ segments of jejunum were transected with a \#11 blade oral to this landmark. The cranial end of each jejunal segment was marked with a $1 \mathrm{~cm}$ transverse cut made with Metzenbaum scissors on the anti-mesenteric surface to mark the orientation of each segment. A total of four jejunal segments per pig were harvested; two were used for each experimental anastomosis with the esophagus and the other two segments were kept as extras in case there was iatrogenic damage to one or both of the first two segments during the experiments. The jejunal mesentery was carefully excised to decrease bunching of the intestine. The esophagus and jejunum segments were randomly assigned a number from 1 to 7 . All esophagus and jejunum segments were rinsed with lactated Ringer's solution (LRS) and stored in LRS in separate sealed plastic bags (Ziplock, S.C. Johnson \& Son, Inc., USA). The intestine and esophagus were kept cooled at $5^{\circ} \mathrm{C}$ overnight until evaluation the following day. All procedures were performed and data collected during one session within 36 hours of euthanasia.

\section{Esophageal anastomosis}

Each esophageal segment was suspended from RochesterPean forceps attached to ring stands separated by $8 \mathrm{~cm}$. For all testing, the cranial segment was always suspended to the right of the evaluator and the caudal segment was placed to the left. A \#11 scalpel blade was used to make a single transverse stab incision on the dorsal surface of the thoracic esophagus $4 \mathrm{~cm}$ from the cranial edge. The transverse incision was extended with Metzenbaum scissors until complete transection was achieved. The esophageal segments were anastomosed to each other using 4-0 polydioxanone sutures (PDS II, Ethicon, USA) on an SH taper needle in a simple interrupted pattern [28]. Each bite was made 2 to $3 \mathrm{~mm}$ from the edge of the anastomosis site. A metric ruler was used to confirm the 2 to $3 \mathrm{~mm}$ spacing between sutures.

\section{Measurement of leak pressure}

Each segment was occluded with Rochester-Pean forceps. Two 18-gauge catheters were inserted into the lumen at the segment ends adjacent to the occluding forceps. The caudal (left side) 18-gauge catheter was connected by standard intravenous tubing to a pressure transducer, a transducer amplifier (ETH 400, CB Sciences Inc., USA), and a pressure monitoring system (PowerLab/4SP, AD Instruments, USA). The transducer was calibrated at the start of the experiment. The cranial (right side) 18-gauge catheter was connected by another intravenous tubing to a syringe pump (Medfusion Model 3500, Smiths Medical, USA) with a $60 \mathrm{~mL}$ syringe filled with LRS. The tubing on both sides was secured to the ring stands with two strips of tape to prevent excessive weight that could have resulted in one or both catheters pulling out of the test segment (Fig. 1A). Once the anastomosis was completed, LRS was infused at a rate of $300 \mathrm{~mL} / \mathrm{h}$ through the caudal 18 -gauge catheter until the incision line leaked. The pressure at which LRS began to leak from the anastomosis site was recorded in $\mathrm{mmHg}$.

\section{Esophageal-jejunal anastomoses}

After the pressure at which leakage occurred was recorded, $1 \mathrm{~cm}$ of tissue was removed from the edge adjacent to the anastomosis of both the cranial and caudal esophageal segments. This was chosen as an arbitrary length that could easily be repeated for every test without losing an excessive amount of the esophageal tissue from the two esophagealjejunal anastomoses. The caudal segment of the esophagus, with the catheter still in place, remained clamped by the Rochester-Pean forceps but was removed from the stand and set aside. A segment of jejunum was clamped with another Rochester-Pean forceps with $5 \mathrm{~cm}$ of tissue between the cranial edge and the forceps. A metric ruler was used to ensure that the forceps were $8 \mathrm{~cm}$ apart. An 18 -gauge catheter, with the transducer attached, was inserted into the jejunum segment. The jejunum and the cranial segment of the esophagus were anastomosed using the same method as previously described for the esophageal-esophageal anastomosis (Fig. 1B). The pressure at which leakage occurred was determined as described above. After testing, both segments were removed from the ring stands.

The remaining caudal segment of the esophagus and a new piece of jejunum were attached to the ring stands in the same fashion as described above. The jejunum was placed on the cranial ring stand with the caudal edge used for anastomosis of the caudal segment of the esophagus that was suspended from the caudal ring stand. An 18-gauge catheter was inserted into the jejunum and attached to the fluid syringe pump as previously described. Similarly, the transducer was attached to the catheter inserted into the caudal esophageal segment as previously described. The same methods for anastomosis and leak pressure testing were used as described above (Fig. 1C). 

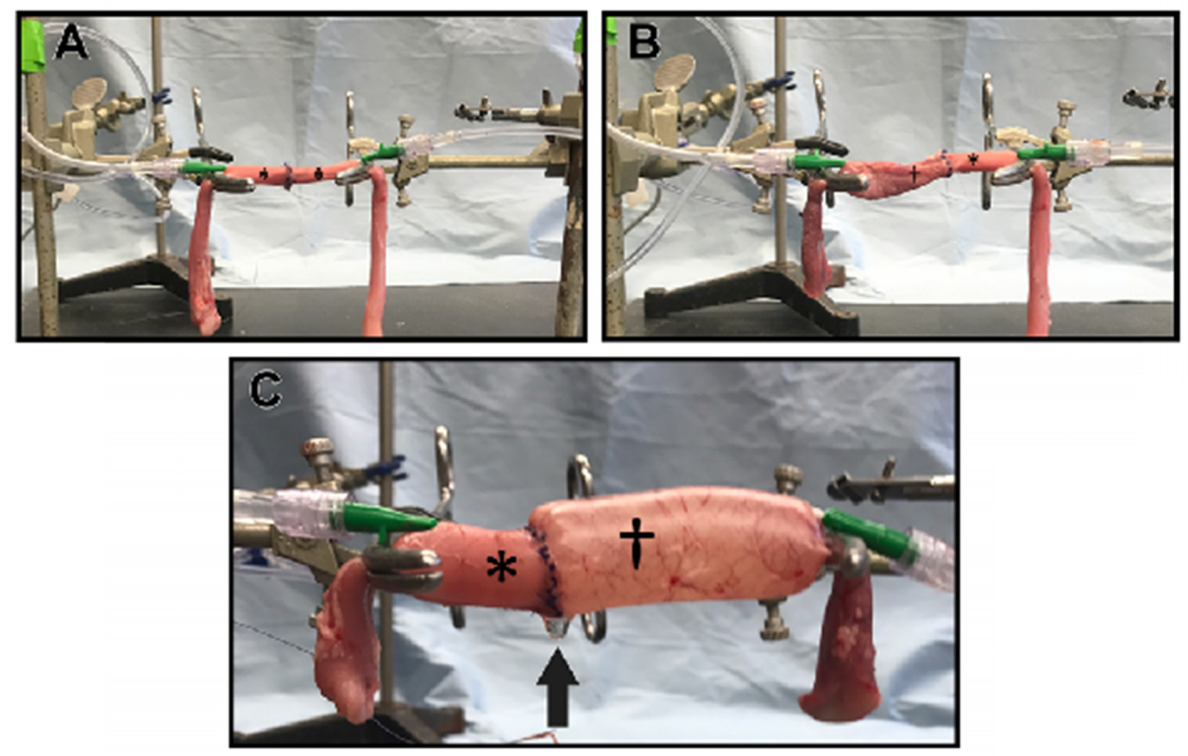

Fig. 1. Experimental setup for anastomoses using cadaveric pig esophagus $\left(^{*}\right)$ and jejunum $\left({ }^{\dagger}\right)$. Cranial segments were attached to the ring stand on the right, whereas caudal segments were attached to the ring stand on the left. (A) esophageal-esophageal anastomosis; (B) cranial esophageal-jejunum anastomosis; and (C) jejunal-caudal esophageal anastomosis after infusion of lactated Ringer's solution. There is fluid accumulation (black arrow) on the ventral aspect of the anastomosis indicating leakage.

\section{Data analysis}

All incisions, anastomoses, and leak pressure tests were performed by a single investigator. The pigs were randomly selected to determine the order in which tissues were tested. The leak pressures for each pig were tested as follows: esophagus-esophagus, cranial esophagus-jejunum, and jejunum-caudal esophagus. The three leak pressure test values and the segment lengths used were recorded and compared.

Leak pressure of the anastomosed segments was defined as the pressure at which the anastomosed segments began to leak at the anastomotic site. In order to standardize measurements among groups, segment length was recorded as the final length of the anastomosed tissues measured between the Rochester-Pean forceps when suspended from the evenly spaced ring stands.

For data analysis, normality and equality of variances of the dependent variables (leak pressure and segment length) were determined by using Brown-Forsythe and Shapiro-Wilk tests, respectively. Leak pressure data met the assumptions of normality and equal variances and were compared among groups using one-way analysis of variance (ANOVA). Segment length data while normally distributed, did not meet the equality of variance assumption and were compared among groups using the Kruskal-Wallis one-way ANOVA on ranks. All analyses were performed using commercial software (SigmaPlot 13.0) with significance declared at $p<0.05$.

\section{Results}

Twenty of 21 anastomoses were successfully completed

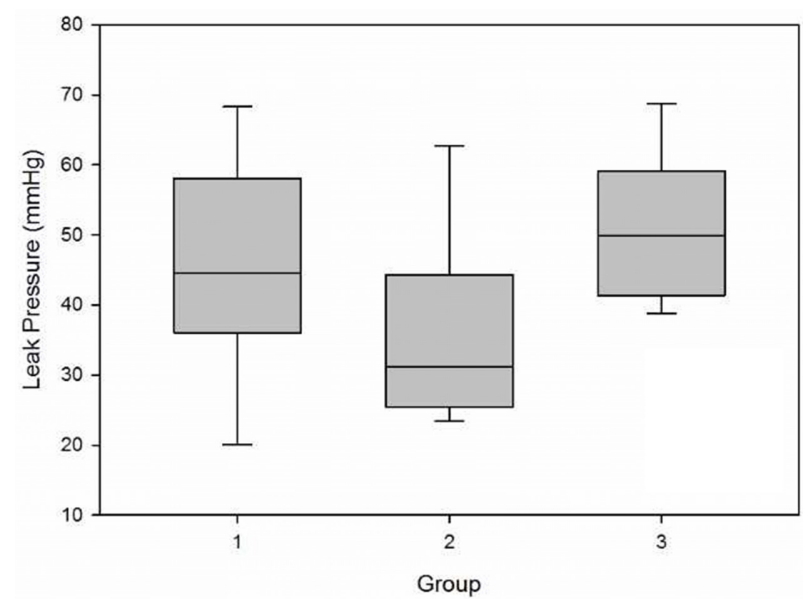

Fig. 2. Box and whisker plot of the leak pressures $(\mathrm{mmHg})$ for the esophageal-esophageal (Group1), cranial esophageal-jejunal (Group 2), and jejunal-caudal (Group 3) anastomoses.

and final group sizes were as follows: esophageal-esophageal anastomosis (Group 1; $\mathrm{n}=7$ ), cranial esophageal-jejunal anastomosis (Group 2; $\mathrm{n}=7$ ), and caudal esophagealjejunal anastomosis (Group 3; $n=6$ ). The caudal esophageal segment from a single pig used in Group 3 was damaged after placement of the catheter and, unfortunately, there was not enough undamaged esophageal tissue remaining to complete the experiment. Segments of jejunum were damaged by the catheter in two instances from 2 pigs and were replaced with a reserved segment from each respective pig.

Median (range) final segment lengths following anastomo- 


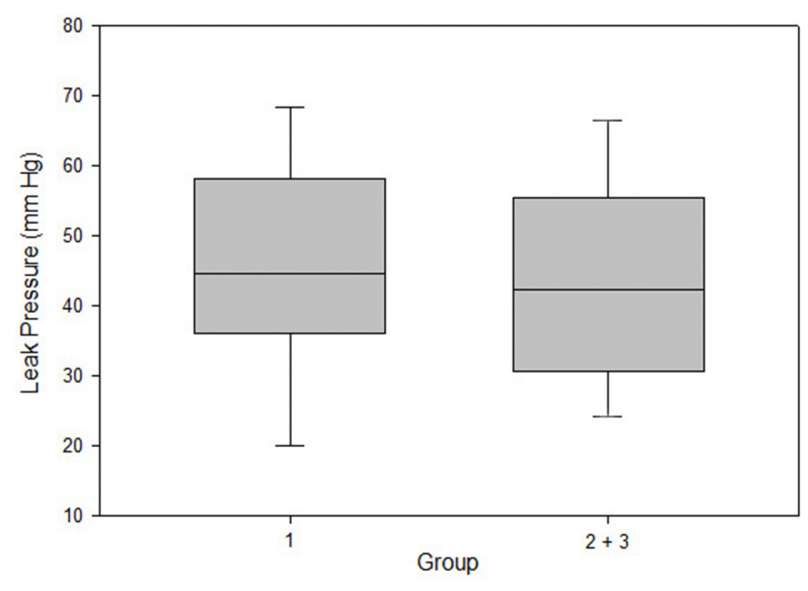

Fig. 3. Box and whisker plot of the leak pressures $(\mathrm{mmHg})$ for Group 1 and groups 2 and 3 combined.

sis were $8.1(7.7$ to 8.3$) \mathrm{cm}, 8.1(7.8$ to 8.3$) \mathrm{cm}$, and $8.1(8.0$ to 8.2$) \mathrm{cm}$ for groups 1,2 , and 3 , respectively ( $p=0.63$ ).

Mean \pm SD leak pressures (Fig. 2) were $46.1 \pm 15.9,36.5 \pm$ 13.6, and $50.9 \pm 11.1 \mathrm{mmHg}$ for groups 1,2 , and 3, respectively $(p=0.18$; power of the performed test with alpha $=$ 0.05: 0.18). To evaluate leak pressure differences between esophageal-esophageal anastomosis and any esophageal-jejunal anastomosis, the results from groups 2 and 3 were combined into a single group, resulting in mean \pm SD leak pressures of $46.1 \pm 15.9$ and $43.1 \pm 14.2 \mathrm{mmHg}$ for esophageal-esophageal and esophageal-jejunal anastomoses (Fig. 3), respectively $(p=0.67$; power of the performed test with alpha $=$ 0.05: 0.07).

\section{Discussion}

Esophageal surgery is associated with a high complication rate, which is even higher when esophageal resection and anastomosis is required, in both human [14,15,17,20-23,29] and veterinary medicine $[8,10,27]$. The poor mobility of the esophagus along with other factors associated with the environment of the esophagus may be associated with the rates of dehiscence and leakage of the surgery site $[1,2,4,12,13,30]$. As such, esophageal replacement with small intestine tissue may be predisposed to similar complications. A recent study by Nucci and Monnet showed that a segment of jejunum supplied by 4 arteries can maintain an adequate blood supply after ligation of 3 of the 4 arteries, making jejunal transposition feasible when based on blood supply. However, in that study, the jejunum was not transected and remained in its normal position [32]. To further investigate this strategy, a logical next step would be to mobilize a jejunal segment by transecting, while preserving the 3 necessary arteries and then anastomose the segment to the esophagus. However, before doing so, understanding the potential for leakage at the anastomosis site should ideally be determined. The present study used leak pressure measurement at the site of anastomosis of cadaveric tissue as a model to determine if an esophagealjejunal anastomosis would be more prone to leakage at the anastomosis site than that of an esophageal-esophageal anastomosis. Leak pressure measurement following luminal distension with fluid provides an estimate of incisional integrity as well as serving as a proxy for the tension placed on the incision site as the intestinal lumen is distended.

Data from the present study showed no significant difference between leak pressure of esophageal-esophageal and esophageal-jejunal anastomoses. There are no previous reports that describe the normal physiologic pressure of the esophagus, let alone an intraluminal pressure at which esophagealjejunal anastomosis is expected to leak. Therefore, it is not possible to know whether the leakages noted in this study occurred at a "supra-physiologic" pressure. Based on the data presented herein, it appears that an esophageal-jejunal anastomosis is unlikely to be any more leak prone than an esophageal-esophageal anastomosis.

Further, there was no significant difference detected between the cranial and caudal esophageal anastomotic sites suggesting that either esophageal segment may be successfully attached to the replacement segment. Leakage has been reported to be more common at the cranial anastomosis when the esophagus is reconstructed with intestinal tissue [7,18,31,32]. Also, an association has been noted between leakage from the cranial anastomosis and stricture formation [33] with one study reporting incidences of $31 \%$ and $39 \%$ for leakage and stricture, respectively, at the cranial anastomosis [31]. There are other factors, such as mechanical movement of the cranial esophagus and pressure differences, which could not be tested in the present study, that are thought to have a role in the high incidence of leakage from the cranial anastomotic site.

Jejunal transposition has become more popular than colonic grafts because the jejunum retains peristaltic activity, prevents gastroesophageal reflux, and will not bellow and cause respiratory distress $[20,23,34]$. The cervical esophagus is susceptible to more movement and strain than the thoracic esophagus, which can lead to breakdown of the anastomotic site [14,17,18,20-23,30-33]. Dehiscence of an esophageal anastomosis may also result from the pressure gradients between the intrathoracic structures and the stomach, particularly during vomiting and defecation $[18,32]$. In one of the few case reports of a dog with an esophageal replacement, there was leakage from the cranial anastomosis following postoperative vomiting, and follow-up surgical repair was required. Shortly after repair of the leaky anastomosis, a sound was heard during defecation and the caudal anastomotic site was found to also have broken down [7].

Dehiscence is the most common cause of death following esophageal surgery; however, mortality rates have varied from $7 \%$ to $80 \%[31,35]$. A recent study showed that resection and anastomosis is associated with a higher risk than an esophagotomy for developing immediate postoperative complications [10]. In that study, the number of dogs that devel- 
oped postoperative dehiscence was low (1/63), but not all dogs that died or were euthanized had a necropsy performed to determine the cause of death. Resection and anastomosis are indicated for multiple types of esophageal lesions, but removal of too much esophageal tissue increases tension and, therefore, the risk for dehiscence and complications [1,6,9].

The thoracic esophagus was chosen for this study because, in pigs, that portion is more plentiful and more easily harvested than the cervical esophagus. Further, the thoracic portion of the esophagus was applicable to our study because this portion is a common area for esophageal lesions in dogs and cats. A common esophageal lesion in dogs and cats is caused by esophageal foreign bodies, which typically lodge in the caudal esophagus or at the level of the heart base $[10,36]$. Lesions that require partial esophagectomy and resection with anastomosis are associated with significantly higher complication rates than lesions that require an esophagotomy [10]. Esophageal replacement may be another treatment option that could be used for extensive lesions of the esophagus that require removal of esophageal tissue [2,4-10,12,30].

The method for closure of the anastomosis in this study was consistent with previously reported information $[1,2,4,9$, $11,12,30]$. Although there is some debate regarding the superiority of single layer over double layer esophageal closure, each technique requires careful suture placement [9]. Singlelayer closure has been shown to be as effective as doublelayer closure, but a more important technical goal is to prevent the mucosal layer from protruding through the suture line [11]. Single-layer closure was chosen in this study due to the challenges associated with closing the esophageal-jejunal anastomosis in a double layer. Moreover, compared to the esophageal submucosa, the jejunal submucosa is not as robust or as easily separated from the muscularis [27].

The present study had multiple limitations. This study was underpowered, so the lack of statistical significance could be attributed to the small sample size. However, when the mean \pm SD esophageal-esophageal anastomosis leak pressures were compared to the combined data for both esophageal-jejunal anastomosis groups (Fig. 3), leak pressures were similar $(46.1 \pm 15.9$ vs. $43.1 \pm 14.2 \mathrm{mmHg})$ suggesting that, from a clinical perspective, when evaluating leak pressure alone, leak pressures are likely to be equivalent between techniques. The use of cadaveric tissue limits the variables that can be investigated such as presence of a food bolus and saliva, changing intrathoracic pressure, and wound healing characteristics, which would require a live animal model.

The present study used swine esophagus and jejunum, tissues with some anatomical differences from dogs that may affect leak pressures. The canine esophagus has striated muscle throughout while the swine esophagus has striated muscle in the cranial part, smooth muscle in the caudal portion, and a mixed population in the middle portion [37]. Differences in muscle type could potentially lead to differences in leak pressure between species or affect the apposition and healing of this type of anastomosis. The physiology of diges- tion is somewhat different between pigs and dogs, but the surgical anatomy of the jejunum, more specifically the submucosa $[27,37,38]$, does not differ appreciably between those species; therefore, differences in jejunal leak pressure between dogs and pigs are not expected. A future study using cadaveric canine tissues, with the same study design, would be useful to not only compare leak pressures between species for this unique anastomosis but also would further validate the use of pigs as a suitable canine model. There may be some differences in healing between the esophageal-jejunal anastomosis of the dog and pig but that is outside the scope of this study. Another limitation is that the cranial and caudal anastomoses were tested separately, whereas in a clinical application esophageal reconstruction would include insertion of a section of jejunum that would be anastomosed at the cranial (oral) and caudal (aboral) end of the jejunal replacement section resulting in two anastomoses. The cranial and caudal anastomoses were performed separately to determine if there was any significant difference in leak pressure between the two hypothetical sites. Hence, the leak pressure model used in this study did not measure leak pressure at both sites simultaneously and thus the study was unable to determine if the cranial site was more prone to leakage. The lack of a difference between leak pressures using the current model for a cranial (oral) and caudal (aboral) anastomosis site may be a reflection of the model, as explained above, or might suggest that differences in leak pressure and anastomosis site failure may only occur in an in vivo context in which complicating factors such as movement, food boluses, saliva, and changes in intrathoracic pressure are present.

In conclusion, these data provide a foundation for future studies on potential treatment options for large esophageal defects in animals. Future studies should determine the normal physiologic pressure of the esophagus and leak pressures following insertion of a section of jejunum into the esophagus with simultaneous evaluation of both cranial (oral) and caudal (aboral) anastomoses. Other factors that can be investigated are factors such as tension and movement that can affect healing of the anastomoses. Investigation of in vivo factors and their effects on the integrity of esophagealjejunal anastomoses and healing of the anastomoses with histological evaluation will be important before the clinical application of esophageal replacement surgery in small animals.

\section{References}

1. Hedlund CS. Surgery of the Esophagus. In: Fossum TW (ed.). Small Animal Surgery. 3rd ed. pp. 372-409, Mosby Elsevier, St. Louis, 2007.

2. Hoffer RE. Principles of Esophageal Surgery. In: Slatter DH (ed.). Textbook of Small Animal Surgery. pp. 654-679, WB Saunders Co., Philadelphia, 1985.

3. Kieves NR, Krebs AI, Zellner EM. A comparison of ex vivo pressures for four enterotomy closures in a canine model. $\mathrm{J}$ Am Anim Hosp Assoc 2018;54:71-76.

4. Waldron DR. Cervical and Thoracic Esophageal Resection 
and Anastomosis. In: Bojrab MJ (ed.). Current Techniques in Small Animal Surgery. 2nd ed. pp. 133-140, Lea and Febiger, Philadelphia, 1983.

5. Bouayad H, Caywood DD, Alyakine H, Lipowitz AJ, Liepold HW. Surgical reconstruction of partial circumferential esophageal defect in the dog. J Invest Surg 1992;5:327-342.

6. Flanders JA. Problems and complications associated with esophageal surgery. Probl Vet Med 1989;1:183-194.

7. Gregory CR, Gourley IM, Bruyette DS, Schultz LJ. Free jejunal segment for treatment of cervical esophageal stricture in a dog. J Am Vet Med Assoc 1988;193:230-232.

8. Pavletic MM. Reconstructive esophageal surgery in the dog: a literature review and case report. J Am Anim Hosp Assoc 1981;17:435-444.

9. Renberg W, Waldron DR. Esophagus. In: Bojrab MJ, Slocum B, Ellison GW (eds.). Current Techniques in Small Animal Surgery. 4th ed. pp. 187-204, Williams and Wilkins, Baltimore, 1998.

10. Sutton JS, Culp WT, Scotti K, Seibert RL, Lux CN, Singh A, Wormser C, Runge JJ, Schmiedt CW, Corrie J, Phillips H, Selmic LE, Nucci DJ, Mayhew PD, Kass PH. Perioperative morbidity and outcome of esophageal surgery in dogs and cats: 72 cases (1993-2013). J Am Vet Med Assoc 2016;249: 787-793.

11. Oakes MG, Hosgood G, Snider TG 3rd, Hedlund CS, Crawford MP. Esophagotomy closure in the dog. A comparison of a double-layer appositional and two single-layer appositional techniques. Vet Surg 1993;22:451-456.

12. Runge JJ, Culp WT. Surgical Treatment of Esophageal Disease In: Monet E (ed.). Small Animal Soft Tissue Surgery. pp. 204-320, John Wiley \& Sons, Hoboken, 2013.

13. Davenport M, Hosie GP, Tasker RC, Gordon I, Kiely EM, Spitz L. Long-term effects of gastric transposition in children: a physiological study. J Pediatr Surg 1996;31:588-593.

14. Linder PA, Sugarbaker DJ. Surgical Procedures to Resect and Replace the Esophagus. In: Zinner M, Ashley SW (eds.). Maingot's Abdominal Operations. 11th ed. pp. 305-330, MacGraw-Hill, Columbus, 2007.

15. Meyers WC, Seigler HF, Hanks JB, Thompson WM, Postlethwait R, Jones RS, Akwari OK, Cole TB. Postoperative function of "free jejunal transplants for replacement of the cervical esophagus. Ann Surg 1980;192:439-450.

16. Muangsombut J, Hankins JR, Mason GR, McLaughlin JS. The use of circular myotomy to facilitate resection and endto-end anastomosis of the esophagus. An experimental study. J Thorac Cardiovasc Surg 1974;68:522-529.

17. Rodgers BM, Talbert JL, Moazam F, Felman AH. Functional and metabolic evaluation of colon replacement of the esophagus in children. J Pediatr Surg 1978;13:35-39.

18. Wilkins EW Jr. Long-segment colon substitution for the esophagus. Ann Surg 1980;192:722-725.

19. Kuzma AB, Holmberg DL, Miller CW, Barker I, Roth J. Esophageal replacement in the dog by microvascular colon transfer. Vet Surg 1989;18:439-445.

20. Bax KM. Jejunum for bridging long-gap esophageal atresia. Semin Pediatr Surg 2009;18:34-39.

21. Cauchi JA, Buick RG, Gornall P, Simms MH, Parikh DH.
Oesophageal substitution with free and pedicled jejunum: short- and long-term outcomes. Pediatr Surg Int 2007;23:1119.

22. Ring WS, Varco RL, L'Heureux PR, Foker JE. Esophageal replacement with jejunum in children: an 18 to 33 year followup. J Thorac Cardiovasc Surg 1982;83:918-927.

23. Shieh HF, Jennings RW. Long-gap esophageal atresia. Semin Pediatr Surg 2017;26:72-77.

24. Curran KM, Fransson BA, Gay JM. A comparison of in situ and in vitro techniques for bursting pressure testing of canine jejunum. Am J Vet Res 2010;71:370-373.

25. Saile K, Boothe HW, Boothe DM. Saline volume necessary to achieve predetermined intraluminal pressures during leak testing of small intestinal biopsy sites in the dog. Vet Surg 2010;39:900-903.

26. Semevolos SA, Reed SK, Gamble K. In vitro bursting pressures of jejunal enterotomy closures in llamas. Vet Surg 2007;36: 64-67.

27. Evans HE, de Lahunta A. Miller's Anatomy of the Dog. Saunders/Elsevier, St. Louis, 2013.

28. Ranen E, Shamir MH, Shahar R, Johnston DE. Partial esophagectomy with single layer closure for treatment of esophageal sarcomas in 6 dogs. Vet Surg 2004;33:428-434.

29. Nicks R. Colonic replacement of the oesophagus. Some observations on infarction and wound leakage. $\mathrm{Br} \mathrm{J}$ Surg 1967;54:124-128.

30. Kyles AE. Esophagus. In: Tobias KM, Johnston SJ (eds.). Veterinary Surgery: Small Animal. pp. 1461-1483, Elsevier, St. Louis, 2012.

31. Bothereau H, Muñoz-Bongrand N, Lambert B, Montemagno S, Cattan P, Sarfati E. Esophageal reconstruction after caustic injury: is there still a place for right coloplasty? Am J Surg 2007;193:660-664.

32. Nucci DJ, Monnet E. Tissue blood flow to a pedicled jejunal autograft in the dog: a pilot study. Vet Surg 2017;46:838842.

33. Saldaña-Cortés JA, Larios-Arceo F, Prieto-Díaz-Chávez E, De Buen EP, González-Mercado S, Alvarez-Villaseñor AS, Prieto-Aldape MR, Fuentes-Orozco C, González-Ojeda A. Role of fibrin glue in the prevention of cervical leakage and strictures after esophageal reconstruction of caustic injury. World J Surg 2009;33:986-993.

34. Gallo G, Zwaveling S, Van der Zee DC, Bax KN, de Langen ZJ, Hulscher JB. A two-center comparative study of gastric pull-up and jejunal interposition for long gap esophageal atresia. J Pediatr Surg 2015;50:535-539.

35. Sale CS, Williams JM. Results of transthoracic esophagotomy retrieval of esophageal foreign body obstructions in dogs: 14 cases (2000-2004). J Am Anim Hosp Assoc 2006;42:450-456.

36. Leib MS, Sartor LL. Esophageal foreign body obstruction caused by a dental chew treat in 31 dogs (2000-2006). J Am Vet Med Assoc 2008;232:1021-1025.

37. Eurell JA, Frappier BL. Dellmann's Textbook of Veterinary Histology. Blackwell Pub, Ames, 2007.

38. Dyce KM, Sack WO, Wensing CJ. Textbook of Veterinary Anatomy. 4th ed. Saunders/Elsevier, St. Louis, 2010. 